\title{
Enantiocontrol in the intermolecular cyclopropanation reaction catalyzed by dirhodium(II) complexes with ortho-metalated aryl phosphine ligands
}

\author{
Mario Barberis, ${ }^{a}$ Pascual Lahuerta, ${ }^{* b}$ Julia Pérez-Prieto*a and Mercedes Sanaú ${ }^{b}$ \\ a Departamento de Química Orgánica/Instituto de Ciencia Molecular, Facultad de Farmacia Universidad de \\ Valencia, Vicént Andrés Estellés s/n, Burjassot, Valencia, 46100 Spain. E-mail: julia.perez@uv.es; \\ Fax: (34)963864939 \\ ${ }^{b}$ Departamento de Química Inorgánica, Facultad de Químicas, Universidad de Valencia, Dr. Moliner 50, 46100 \\ Burjassot,Valencia, Spain. E-mail: pascual.lahuerta@uv.es; Fax: (34)963864322
}

\section{Received (in Liverpool, UK) 8th December 2000, Accepted 25th January 2001 First published as an Advance Article on the web 14th February 2001}

$(P)$ and $(M)$ dirhodium(II) complexes with ortho-metalated aryl phosphines are assessed as chiral catalysts in the enantioselective cyclopropanation of styrenes by ethyl diazoacetate; enantioselectivities up to $91 \%$ and up to $87 \%$, respectively, for cis- and trans-2-arylcyclopropanecarboxylates are observed.

A great deal of effort is presently being devoted to the development of new chiral catalysts to induce enantiocontrol in carbene transfer reactions. ${ }^{1-3}$ The catalytic reaction of ethyl diazoacetate with styrene is a model reaction with which stereoand enantioselectivity for intermolecular cyclopropanation is measured and catalytic effectiveness is determined. Chiral copper catalysts, ${ }^{4-8}$ especially those with bis-oxazoline ligands and ruthenium catalysts, ${ }^{9}$ have been found to induce the highest levels of enantiocontrol. Thus, enantioselectivities up to $99 \%$ for ethyl 2-phenylcyclopropanecarboxylates have been obtained in the cyclopropanation of styrene with ethyl diazoacetate catalyzed by $\mathrm{Cu}$ catalysts. In general, chiral dirhodium(II) catalysts do not provide high enantioselectivities; there is a remarkable exception in chiral azetidine-4-carboxylate-ligated dirhodium(II) catalysts. ${ }^{10}$ They produce enantioselectivities up to 76 and $52 \%$ ee, respectively, for $\mathbf{2 a}$ and $\mathbf{3 a}$ (Scheme 1). $\dagger$

Dirhodium(II) catalysts of general formula $\mathrm{Rh}_{2}\left(\mathrm{O}_{2} \mathrm{CR}\right)_{2}(\mathrm{PC})_{2}$, containing two ortho-metalated aryl phosphines (PC) in a head to tail arrangement, ${ }^{11}$ (Fig. 1), have backbone chirality and they can be isolated as pure enantiomers by conventional resolution methods. ${ }^{12}$ Until now, all approaches to the design of enantiomerically pure $\mathrm{Rh}$ (II) catalysts have depended on the attachment of enantiomerically pure ligands to the dirhodium core.

The racemic $\mathrm{Rh}_{2}\left(\mathrm{O}_{2} \mathrm{CR}\right)_{2}(\mathrm{PC})_{2}$ compounds have been used in intramolecular processes. ${ }^{13,14}$ Those with high electronwithdrawing carboxylate groups $\left(\mathrm{CF}_{3} \mathrm{CO}_{2}\right)$ have shown the best selectivity values.

We now report, from results obtained with a series of $\mathrm{Rh}(\mathrm{II})$ catalysts, $\mathrm{Rh}_{2}\left(\mathrm{O}_{2} \mathrm{CCF}_{3}\right)_{2}(\mathrm{PC})_{2}$, that they induce low diastereoselectivity in the intramolecular cyclopropanation of styrenes 1a-1d (Scheme 1), but both cyclopropane diastereoisomers are obtained with high optical purity.

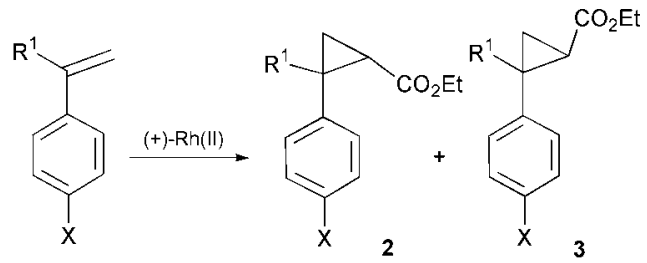

1a $X=H, R^{1}=H$

1b $X=\mathrm{Cl}, \mathrm{R}^{1}=\mathrm{H}$

1c $X=O M e, R^{1}=H$

1d $X=H, R^{1}=M e$

Scheme 1 Catalyzed cyclopropanation of styrenes.
Use of catalysts 4-8 for cyclopropanation of styrene with ethyl diazoacetate gave the results reported in Table 1 (Fig. 1). Catalysts 4-7 showed low diastereoselectivity in the obtention of both diastereoisomers, 2a and 3a. However, all of them induced high asymmetry in the cyclopropanation of styrene; those catalysts with a more basic phosphine (catalysts 4-6 compared to 7) led to the best ee values. The influence of the olefin on enantioselectivity was studied using styrenes of varying nucleophilicity (Table 2). Product yields were higher with the more nucleophilic olefins 1c and 1d. However, no remarkable differences on diastero- and enantioselectivity were found for catalysts 4-7. These results confirm that degradation to an achiral rhodium catalyst is not a major competing pathway.

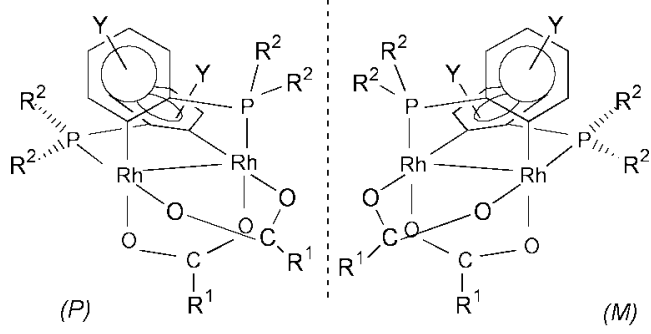

\begin{tabular}{ccccc}
\hline Rh & $\begin{array}{c}\text { Phosphine } \\
\mathrm{Ar}_{3} \mathrm{P}(\mathrm{Ar})\end{array}$ & $\mathrm{R}^{1}$ & $\mathrm{R}^{2}$ & $\mathrm{Y}$ \\
\hline $\mathbf{4}$ & $\mathrm{C}_{6} \mathrm{H}_{5}$ & $\mathrm{CF}_{3}$ & $\mathrm{C}_{6} \mathrm{H}_{5}$ & $\mathrm{H}$ \\
$\mathbf{5}$ & $p-\mathrm{MeC}_{6} \mathrm{H}_{4}$ & $\mathrm{CF}_{3}$ & $p-\mathrm{MeC}_{6} \mathrm{H}_{4}$ & $\mathrm{CH}_{3}$ \\
$\mathbf{6}$ & $m-\mathrm{MeC}_{6} \mathrm{H}_{4}$ & $\mathrm{CF}_{3}$ & $m-\mathrm{MeC}_{6} \mathrm{H}_{4}$ & $\mathrm{CH}_{3}$ \\
$\mathbf{7}$ & $p-\mathrm{FC}_{6} \mathrm{H}_{4}$ & $\mathrm{CF}_{3}$ & $p-\mathrm{FC}_{6} \mathrm{H}_{4}$ & $\mathrm{~F}$ \\
$\mathbf{8}$ & $\mathrm{C}_{6} \mathrm{H}_{5}$ & $\mathrm{C}\left(\mathrm{C}_{6} \mathrm{H}_{5}\right)_{3}$ & $\mathrm{C}_{6} \mathrm{H}_{5}$ & $\mathrm{H}$
\end{tabular}

Fig. 1 List of $\mathrm{Rh}(\mathrm{II})$ catalysts with ortho-metalated aryl phosphine ligands.

Table 1 Asymmetric cyclopropanation of styrene catalyzed by the $(M)$ enantiomer

\begin{tabular}{|c|c|c|c|c|c|c|}
\hline \multirow[b]{2}{*}{$\mathrm{Rh}$} & \multirow[b]{2}{*}{ Yield $\%^{a}$} & \multicolumn{3}{|l|}{$\%$ ee } & \multicolumn{2}{|c|}{ Configuration } \\
\hline & & $\mathbf{2} \mathbf{a} / \mathbf{3} \mathbf{a}^{b}$ & $\mathbf{2} \mathbf{a}^{c}$ & $\mathbf{3} \mathbf{a}^{c}$ & $2 \mathbf{a}^{d}$ & $3 \mathbf{a}^{d}$ \\
\hline 4 & 55 & $48: 52$ & 91 & 87 & $1 S, 2 R$ & $1 S, 2 S$ \\
\hline 5 & 40 & $61: 39$ & 87 & 75 & $1 S, 2 R$ & $1 S, 2 S$ \\
\hline 6 & 36 & $51: 49$ & 88 & 81 & $1 S, 2 R$ & $1 S, 2 S$ \\
\hline 7 & 71 & $47: 53$ & 74 & 74 & $1 S, 2 R$ & $1 S, 2 S$ \\
\hline 8 & 94 & $43: 57$ & 39 & 6 & $1 R, 2 S$ & $1 R, 2 R$ \\
\hline
\end{tabular}

${ }^{a}$ Cyclopropanation yield based on ethyl diazoacetate. ${ }^{b}$ Determined by GC analysis. ${ }^{c}$ Ee values were based on GC analysis with a 2,3-di- $O$-acetyl-6- $O$ tert-butyldimethylsilyl-beta-CDX column. ${ }^{d}$ Configuration was determined by correlation of the sign of the rotation of polarized light with that of the known enantiomer (ref. 15). 
Table 2 Influence of the olefin on enantioselectivity in the cyclization catalyzed by $(\boldsymbol{M})-\mathbf{4}$

\begin{tabular}{|c|c|c|c|c|}
\hline \multirow[b]{2}{*}{ Olefin } & \multirow[b]{2}{*}{ Yield \% } & \multicolumn{3}{|l|}{$\%$ ee } \\
\hline & & $2 / 3$ & 2 & 3 \\
\hline 1a & 55 & $48: 52$ & 91 & 87 \\
\hline $1 b$ & 62 & $49: 51$ & 86 & $-^{a}$ \\
\hline 1c & 88 & $51: 49$ & $-a$ & 85 \\
\hline 1d & 90 & $51: 49$ & 84 & $-a$ \\
\hline$a$ Not determ & & & & \\
\hline
\end{tabular}

We suggest that the olefin approaches to the carbenoid through its less substituted carbon and also that the carbene transfer to olefin occurs through an early transition state. The interaction between the carbenoid ester group $\left(\mathrm{CO}_{2} \mathrm{Et}\right)$ and the olefinic substituents ( $R$, Ar) would be weak in such a case. These two mechanistic details, altogether, could explain the low influence of the olefin on diastereoselectivity observed in our experiments.

A tentative rationale for the observed high ee values for both stereoisomers, and for the sense of asymmetric induction in the cyclopropanation of styrenes with Rh(II) catalysts 4-7 is based on the model depicted in Fig. 2 for the $M$-catalyst. The nonmetalated aryl substituents of the phosphorus atom protrude into the region where carbene transfer takes place, thereby limiting the possible orientations of the coordinated carbene and favoring those orientations placing the ester group at the less sterically demanding quadrants (orientation $\mathbf{A}_{\mathbf{1}}$ and $\mathbf{B}_{\mathbf{1}}$ in Fig. 2 ). The cyclopropanation step, $\mathbf{A}_{\mathbf{1}} \rightarrow \mathbf{A}_{\mathbf{2}}$ appears to be more favored than $\mathbf{B}_{\mathbf{1}} \rightarrow \mathbf{B}_{\mathbf{2}}$, since in the latter, a repulsive interaction builds up between the ester group and the metalated aryl group at some level of the proccess.

Additional evidence supporting such a model was obtained from the crystal structure determination of the enantiomerically pure catalyst $(\boldsymbol{M})-\mathbf{8}$ having bulky carboxylate ligands

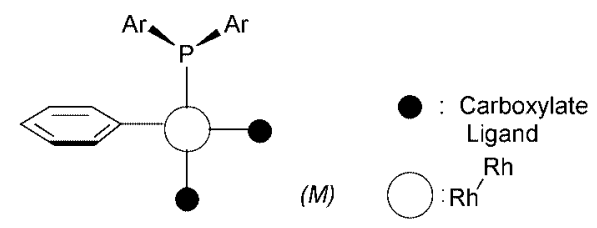

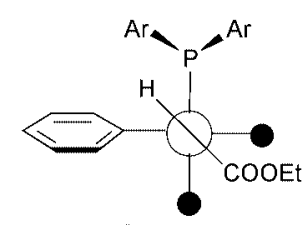

$A_{1}$<smiles></smiles><smiles>[Te]P[Te]</smiles><smiles>CCOC(=O)c1ccc(C(c2ccccc2)c2ccccc2)cc1</smiles>

0
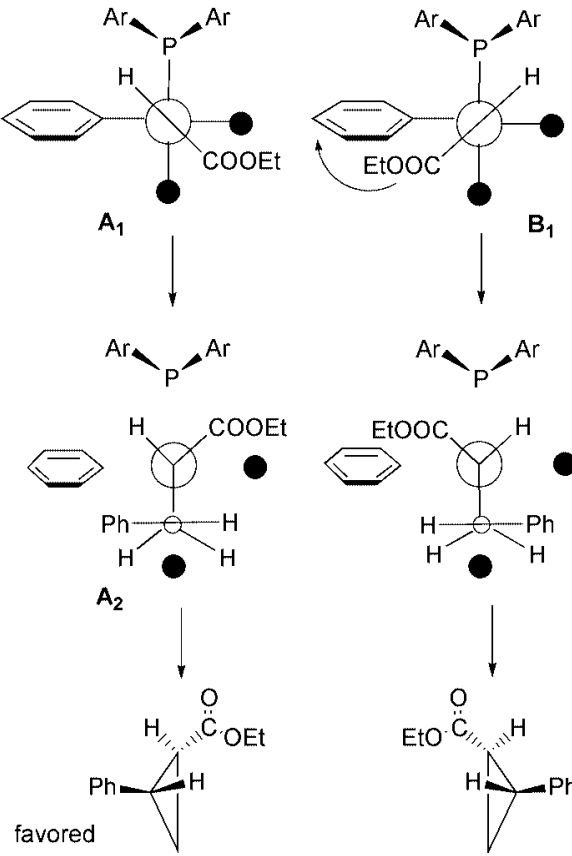

$\mathbf{B}_{1}$
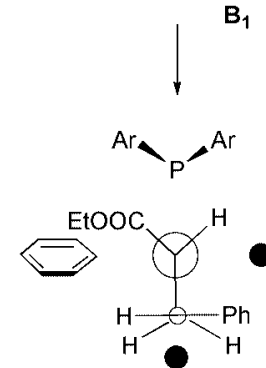

$\mathrm{B}_{2}$

$\mathrm{O}$

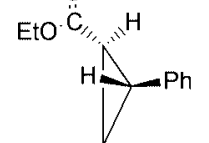

Fig. 2 Model transition state for the reaction of styrene catalyzed by the $(M)$ enantiomer.

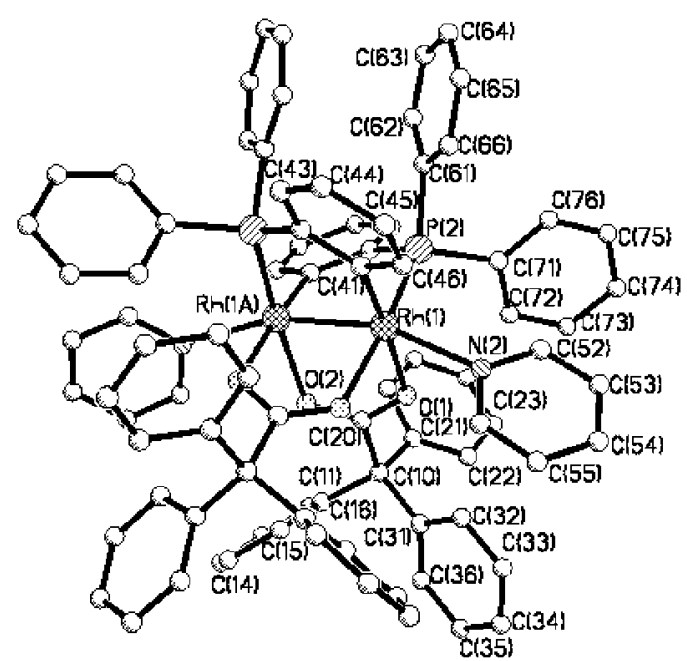

Fig. 3 Molecular view of the complex $\mathrm{Rh}_{2}\left[\left(\mathrm{C}_{6} \mathrm{H}_{5}\right)_{3} \mathrm{CCO}_{2}\right]_{2}\left[\left(\mathrm{C}_{6} \mathrm{H}_{5}\right)_{2}\left(\mathrm{C}_{6} \mathrm{H}_{4}\right) \mathrm{P}\right]_{2}[(\boldsymbol{M})-8]$. Selected distances $(\AA)$ are $\mathrm{Rh}(1)-\mathrm{Rh}(1 \mathrm{~A})=2.5587(7), \mathrm{Rh}(1)-\mathrm{O}(2)=2.151(3), \mathrm{Rh}(1)-\mathrm{O}(1)=$ $2.164(3), \mathrm{Rh}(1)-\mathrm{P}(2)=2.280(13), \mathrm{Rh}(1)-\mathrm{N}(2)=2.302(4)$. Selected angles $\left(^{\circ}\right)$ are $\mathrm{C}(41)-\mathrm{Rh}(1)-\mathrm{O}(2)=88.08(15), \mathrm{O}(2)-\mathrm{Rh}(1)-\mathrm{O}(1)=$ $85.65(12), \quad \mathrm{O}(2)-\mathrm{Rh}(1)-\mathrm{P}(2)=171.46(9), \quad \mathrm{N}(2)-\mathrm{Rh}(1)-\mathrm{Rh}(1 \mathrm{~A})=$ 162.02 .

$\left[\left(\mathrm{C}_{6} \mathrm{H}_{5}\right)_{3} \mathrm{CCO}_{2}\right]$ (Fig. 3). In this case two relevant observations are made: the enantioselectivity was much lower (almost zero for one of the diastereoisomers) and there was a reversal of induction. These two facts may be attributed to increased steric interactions in the area of the carboxylate ligands, due to the higher steric requirements of the $\left[\left(\mathrm{C}_{6} \mathrm{H}_{5}\right)_{3} \mathrm{CCO}_{2}\right]$ in 8 compared to $\left(\mathrm{CF}_{3} \mathrm{CO}_{2}\right)$ in 4-7, that make a carbenoid intermediate $\mathbf{A}_{\mathbf{1}}$ less favored than $\mathbf{B}_{1}$ (Fig. 2). Additional studies oriented to confirm the reliability of the model depicted in Fig. 2 are in progress.

In summary, results indicate a high chiral recognition in the intermolecular cyclopropanation of styrenes showed by these dirhodium(II) compounds. The ee values clearly exceed those previously observed with other $\mathrm{Rh}$ (II) catalysts for this particular intermolecular reaction.

We thank the Dirección General de Investigación Científica y Técnica (DGICYT) (Project PB98-1437) and the EC (Project TMR Network ERBFMRXCT 60091).

\section{Notes and references}

$\dagger$ CCDC 155434. See http://www.rsc.org/suppdata/cc/b0/b010145c/ for crystallographic files in .cif format.

1 M. P. Doyle and M. N. Protopopova, Tetrahedron, 1998, 54, 7919.

2 M. P. Doyle and D. C. Forbes, Chem. Rev., 1998, 98, 911.

3 G. A. Sulikowski, K. L. Cha and M. M. Sulikowski, Tetrahedron: Asymmetry, 1998, 9, 3145.

4 T. Aratani, Y. Yoneyoshi and T. Nagase, Tetrahedron Lett., 1982, 23, 685.

5 Z. Li, Z. Zheng and H. Chen, Tetrahedron: Asymmetry, 2000, 11, 1157.

6 D. A. Evans, K. A. Woerpel, M. M. Hinman and M. M. Faul, J. Am. Chem. Soc., 1991, 113, 726.

7 R. E. Lowenthal, A. Abiko and S. Masamune, Tetrahedron Lett., 1990, 31, 6005 .

8 H. Fritschi, U. Leutenegger and A. Pfaltz, Helv. Chim. Acta, 1988, 71, 1553.

9 H. Nishiyama, N. Soeda, T. Naito and Y. Motoyama, Tetrahedron: Asymmetry, 1998, 9, 2865

10 M. P. Doyle, S. B. Davies and W. Hu, Chem. Comm., 2000, 867.

11 A. R. Chakravarty, F. A. Cotton, D. A. Tocher and J. H. Tocher, Organometallics, $1985, \mathbf{4}, 8$.

12 D. F. Taber, S. C. Malcolm, S. K. Bieger, P. Lahuerta, S.-E. Stiriba, J. Pérez-Prieto, M. Sanaú and M. A. Monge, J. Am. Chem. Soc., 1999, 121, 860.

13 F. Estevan, P. Lahuerta, J. Pérez-Prieto, M. Sanaú, S. E. Stiriba and M. A. Ubeda, Organometallics, 1997, 16, 880.

14 F. Estevan, P. Lahuerta, J. Pérez-Prieto, I. Pereira, S. E. Stiriba and M. A. Ubeda, Organometallics, 1998, 17, 3442.

15 T. Aratani, Y. Nakanisi and H. Nozaki, Tetrahedron, 1970, 26, 1675. 